EUROPEAN UNIVERSITY INSTITUTE, FLORENCE

DEPARTMENT OF LAW

EUI Working Paper LAW No. 99/6

Global Economic Networks and Global Legal Pluralism

FRANCIS SNYDER

BADIA FIESOLANA, SAN DOMENICO (FI) 
All rights reserved.

No part of this paper may be reproduced in any form without permission of the author.

(C) 1999 Francis Snyder

Printed in Italy in August 1999

European University Institute

Badia Fiesolana

I - 50016 San Domenico (FI)

Italy 


\section{ACKNOWLEDGMENTS}

Early versions of this paper were presented at the Institute of International Studies, Stanford University, 2 April 1999, while I was Visiting Senior Fellow at the Stanford Law School Program in International Legal Studies; the Conference on 'Transatlantic Regulatory Cooperation', Inaugural Conference of the European Studies Center of New York, held at Columbia Law School, 16-17 April 1999; the Conference on 'The Regional and Global Regulation of International Trade', Institute of European Studies of Macau, 10-11 May 1999; and the Guandong International Research Institute for Technology and Economy, 13 May 1999, Guangzhou, China. I am grateful for comments and discussion on these occasions. I wish to thank in particular George Bermann, Coit Blacker, Maria do Ceu Esteves, Chen Yong Quan, Cao Ge Feng, Candido Garcia Molyneux, Tom Heller, David Holloway, Emir Lawless, Cosimo Monda, Anne-Lise Strahtmann, Yang Zugong, the Hong Kong Trade Development Council, and several government and toy industry representatives in the Shenzhen, China, Special Economic Zone, for their contributions to the paper. This paper will be published in: George Bermann, Matthias Hedeger, and Peter Lindseth (eds), Transatlantic Regulatory Cooperation, Oxford University Press, Oxford, 2000). I am pleased to acknowledge the agreement of the editors of this volume concerning the inclusion of the paper in the EUI Working Papers series. 
1. INTRODUCTION ...................................................................................................

2. THE MEANING OF GLOBALISATION ..........................................................6

3. A GLOBAL ECONOMIC NETWORK: THE GLOBAL COMMODITY CHAIN IN TOYS .....................................................................................................8

4. THE SHAPE OF GLOBAL LEGAL PLURALISM......................................... 14

5. GLOBAL LEGAL PLURALISM AND THE GLOBAL COMMODITY CHAIN IN TOYS ................................................................................................... 17

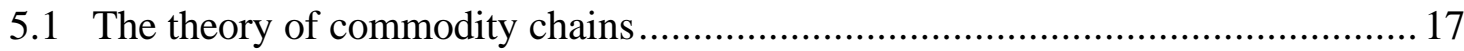

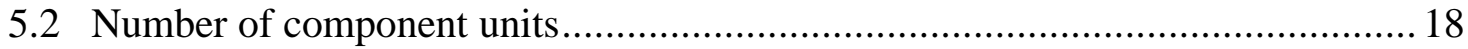

5.3 Geographic concentration or dispersal ....................................................... 19

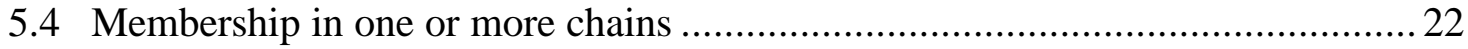

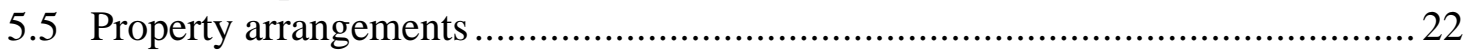

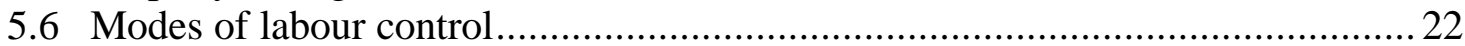

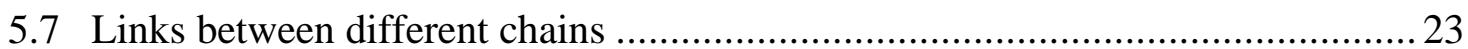

5.8 Connections between economic relations and specific sites............................ 24

5.9 Relations between sites and the chain as a whole ...................................... 25

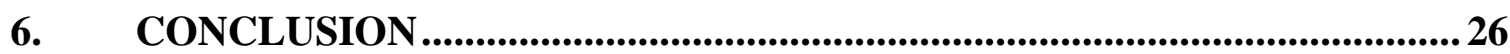




\title{
GLOBAL ECONOMIC NETWORKS AND GLOBAL LEGAL PLURALISM
}

\author{
Francis Snyder*
}

\section{Introduction}

How are global economic networks - including transatlantic economic networks - governed? I suggest that they are governed by the totality of strategically determined, situationally specific, and often episodic conjunctions of a multiplicity of sites throughout the world. These sites have institutional, normative, and processual characteristics. The totality of these sites represents a new global form of legal pluralism. This paper aims to explore and, within limits, to substantiate this claim. It invites us to think systematically about how global economic networks are governed by global legal pluralism.

This paper forms part of a broader research project on the governance of globalisation. The project analyses the resolution of trade disputes between the European Union (EU) and China. ${ }^{1}$ It focuses on a series of case studies,

\footnotetext{
* Professor of European Community Law, European University Institute, Florence: CoDirector, Academy of European Law, Florence; Professor of Law, College of Europe, Bruges: Honorary Visiting Professor of Law, University College London.

${ }^{1}$ For other publications from the project, see: Francis Snyder, 'Legal Aspects of Trade between the European Union and China: Preliminary Reflections', in Nicholas Emiliou and David O'Keeffe (ed), The European Union and World Trade Law after the GATT Uruguay Round (John Wiley \& Sons, Chichester, 1996), pp 363-377; Francis Snyder, International Trade and Customs Law of the European Union (Butterworths, London,
} 
one of which concerns the international trade in toys between the EU and China. Here I draw on this case study briefly and selectively for the purpose of my theoretical argument. Though based on a specific example, this theoretical argument also applies to transatlantic regulatory cooperation between the United States and the European Union.

The paper aims to increase our understanding of how global economic networks are governed and improve our capacity to analyse these new forms of governance, rather than to promote law reform or advance a specific political or institutional agenda. Consequently, its perspective is more sociological than normative. It adopts, for the most part, the standpoint of strategic actors. Relations among strategic actors can be envisaged as involving different types of organisations, whether firms, states, or regional or international organisations. Alternatively, we can see them as implicating different structures of governance, whether market-based, polity-based, or based on conventions in the form of international agreements. From a third perspective, these relationships put into play global economic networks and various sites of global legal pluralism. The paper is intended to highlight all of these perspectives.

1998), pp 594-600 and passim; Francis Snyder, 'Europeanisation and Globalisation as Friends and Rivals: European Union Law and Global Economic Networks', in Francis Snyder (ed), The Europeanisation of Law (Hart Publishing, Oxford, in press); Francis Snyder, 'Governing Globalisation: The European Union in the Global Legal Arena', (1999) 5 European Law Journal, Special Issue on 'Globalisation and Law', forthcoming; Francis Snyder, 'Legal Issues in EU-China Trade Relations', Wuhan University Law Review, forthcoming 1999 [in Chinese]; and Francis Snyder and Song Ying, Introduction to European Union Law, $2^{\text {nd }}$ edition (Peking University Press, Beijing, forthcoming 2000 [in Chinese]). 
The remainder of the paper is divided into four main parts. The next part (Part 2) discusses the meaning of globalisation. Part 3 introduces the global commodity chain in toys, which provides an empirical anchor for the theoretical argument. Part 4 then summarises the basic theoretical argument regarding global legal pluralism. Part 5 identifies some of the sites of global legal pluralism which are the most significant for this global economic network. On the basis of this discussion, the conclusion sets forth a series of hypotheses for future research.

\section{The meaning of globalisation}

Thinking about how global economic networks are governed requires a concept of globalisation. By globalisation, I refer to an aggregate of multifaceted, uneven, often contradictory economic, political, social and cultural processes which are characteristic of our time. This paper concentrates primarily on the economic aspects, but these need to be set within a more general framework.

In economic terms, the most salient features of globalisation, driven by multinational firms, are for the present purposes the development of international production networks (IPNs), dispersion of production facilities among different countries, the technical and functional fragmentation of production, the fragmentation of ownership, the flexibility of the production process, worldwide sourcing, an increase in intra-firm trade, the interpenetration of international financial markets, the possibility of virtually instantaneous worldwide flows of information, changes in the nature of employment, and the emergence of new forms of work. 
Viewed from a political standpoint, globalisation has witnessed the rise of new political actors such as multinational firms, non-governmental organisations and social movements. It has tended to weaken, fragment, and sometimes even restructure the state, but has not by any means destroyed or replaced it. Globalisation has also altered radically the relationship to which we have become accustomed in recent history between governance and territory. It thus has blurred and splintered the boundaries between the domestic and external spheres of nation-states and of regional integration organisations; fostered the articulation of systems of multi-level governance, interlocking politics and policy networks; and helped to render universal the discourse of and claims for human rights. In many political and legal settings, such as the European Union, it has raised serious questions about the nature and appropriate form of contemporary governance.

Among the manifold social processes involved in globalisation are the spread of certain models of production and patterns of consumption from specific geographic/political/national contexts to others. Contradictory tendencies have developed towards internationalisation and localisation within as well as among different regions and countries. We have also witnessed the uneven development of new social movements based on different, if not alternative, forms of community.

Seen as a cultural phenomenon, globalisation has implied the emergence of a new global culture, which is shared to some extent by virtually all elite groups. This has enhanced the globalisation of the imagination and of the 
imaginable. $^{2}$ At the same time it has contributed to the marginalisation of many local cultures. Consequently, it has sometimes increased the range and depth of international and infranational cultural conflicts, as well as resistance to new forms of cultural imperialism.

\section{A global economic network: the global commodity chain in toys}

Global economic networks take various forms. I focus here on the international toy industry. The Barbie doll illustrates the toy industry's domestic impact and global reach. In European countries, imports of toys from Asia have sometimes provoked reactions bordering on xenophobia. In the United States they have triggered outrage against cheap Chinese labour and trade deficits with China, which in the case of the toy trade between China and the USA was claimed by the US to amount to US $\$ 5.4$ billion. $^{3}$ This has not, however, been true by and large of the Barbie doll, which is usually viewed instead as a United States or even global product.

The Barbie doll's label says 'made in China'. This suggests, correctly, that, in the production of Barbie, China provides the factory space, labour, and electricity, as well as cotton cloth for the dress. It conceals, however, the facts that Japan supplies the nylon hair, Saudia Arabia provides oil, Taiwan refines oil into ethylene for plastic pellets for the body, Japan, the US, and Europe supply almost all the machinery and tools, most of the molds (the

\footnotetext{
${ }^{2}$ For this expression, I am indebted to Prof. Pietro Barcellona, oral intervention at the Conference on 'Quelle culture pour l'Euope? Ordres juridiques et cultures dans le processus de globalisation', Réseau Européen de Droit et Société (REDS) and Istituto di Ricerca sui Problemi dello Stato e delle Istitutionzi (IRSI), Rome, 2-3 November 1998.

${ }^{3}$ Rone Tempest, 'Barbie and the World Economy', Los Angeles Times World Report [A Special Section Produced in Cooperation with The Korea Times], Sunday, October 13,
} 
most expensive item), come from the US, Japan, or Hong Kong, the United States supplies cardboard packaging and paint pigments, and Hong Kong provides supplies the banking and insurance and carries out the delivery of the raw materials to factories in south China together with the collection of the finished products and shipping. Two Barbie dolls are marketed every second in 140 countries around the world by Mattel Inc. of El Segundo, Callifornia. In Palo Alto, California there is a Barbie doll museum. Barbie celebrated her $40^{\text {th }}$ birthday on March 9, 1999, and the US Post Office released a commemorative U.S. postage stamp in June in her honour. ${ }^{4}$ The Barbie doll is quintessentially American in origin, style and culture, and of course is the result of a global commodity chain powered by a US buyer. But Barbie is a global product, if by 'global' we refer to the fragmentation of the production process, the dispersion of production facilities among different countries, and the organisation of production within international production networks.

We can understand this industry most easily by conceiving of it as a global commodity chain. By 'commodity chain', I mean 'a network of labor and production processes whose end result is a finished commodity'. ${ }^{5}$ Global commodity chains tend to be strongly connected to specific systems of production and to involve particular patterns of coordinated trade. ${ }^{6}$

1996, p 3.

${ }^{4}$ Elizabeth Rapoport, 'Barbie at 40', Sky (Delta Air Lines), March 1999, 54-57.

${ }^{5}$ Terence K Hopkins and Immanuel Wallerstein, 'Commodity Chains in the WorldEconomy Prior to 1800', Review, 10, 1986, 157-170 at 159.

${ }^{6}$ Gary Gereffi, 'The Organization of Buyer-Driven Global Commodity Chains: How U.S. Retailers Shape Overseas Production Networks', in Gary Gereffi and Miguel Korzeniewicz (ed), Commodity Chains and Global Capitalism (Greenwood Press, 
Each global commodity chain, if we follow Gereffi's widely accepted schema, has three main dimensions. The first refers to the structure of inputs and outputs: products and services are linked together in a sequence in which each activity adds value to its predecessor. The second concerns territoriality; networks of enterprises may be spatially dispersed or concentrated. The third dimension is the structure of governance: relationships of power and authority determine the flow and allocation of resources (financial, material, human) within the chain. ${ }^{7}$

Here we are interested especially in the third dimension, the structure of governance. Gereffi distinguishes two distinct types of governance structures in global commodity chains. On the one hand are producer-driven commodity chains, in which the system of production is controlled by large integrated industrial enterprises. On the other hand are buyer-driven commodity chains, in which production networks are typically decentralised and power rests with large retailers, brand-name merchandisers and trading companies. ${ }^{8}$ This distinction provides a useful point of departure for analysing the global commodity chain in the EU-China toy trade.

The international toy industry is a prime example of an international commodity chain dominated by the buyers. It is hierarchically organised. At the top of the hierarchy are large buyers as well as large retailers. The buyers include several US manufacturers, two Japanese manufacturers, and one European company. The most important buyers are two American

\footnotetext{
Westport, CN, 1994) 95-122 at 96.

${ }^{7}$ Gereffi, 'The Organization...', at 96-97.

${ }^{8}$ Gereffi, 'The Organization...', at 97.
} 
companies, Mattel and Hasbro. The key elements in the power of buyers are designs and brands. The large buyers are the node in various networks of inventors and creators of toys. Through contract, they control the access of inventors, intermediaries, and factories to the market.The most important retailers include large specialist stores such as Toys "R" Us, discount houses such as Wal-Mart in the US, and hypermarkets or catalogue stores in the EU. Taking buyers and retailers together, the power of this group lies in its control of design, brands, and marketing.

Buyers and retailers compete, however, with regard to access to retail markets. The powerful buyers are dependent to some degree on large retailers, such as Toys "R" Us. With regard to the retail market, as economic downturns reveal, the two groups have conflicting interests. To maintain market share, and to enhance their dominant position in the global commodity chain, buyers have tried recently to lessen their dependence on retailers. Their strategies for doing so include increased direct-to-consumer sales, such as catalogs and Internet sales, either from their own website or from online retailers. ${ }^{9}$

The US firms have regional headquarters and a significant share of the toy market in Europe. The European Union toy market is supplied mainly through importer-wholesalers. As of 1995, the EU toy industry comprised about 2600 firms, producing a great variety of toys, and employing just under 100,000 workers, with only 15 firms having more than 500

\footnotetext{
${ }^{9}$ See George Anders and Lisa Bannon, 'Etoys to join web-retailer parade with IPO', The Wall Street Journal. Tuesday, April 6, 1999, p B1.
} 
employees. ${ }^{10}$ Each country has its own distinctive retail sector, varying from catalogue stores through hypermarkets to independent retailers. ${ }^{11}$ Except for Lego, established in Denmark in 1932 and now one of the world's ten largest toy manufacturers, there are no large manufacturers or specialist retailers based in Europe similar to those based in the USA. Together with LEGO and the Japanese firm Bandai, the US firms dominated the first main peak trade association, Toy Manufacturers of Europe, formed in the early 1990s, and are now the principal players in the current EU peak association, Toy Industries of Europe (TIE).

Further down the hierarchy come the Hong Kong companies which act as intermediaries between these multinationals and the toy factories. In East Asia, Hong Kong has been of signal importance in the development of the toy industry. Its role first started in the 1940s as an export platform, then developed in the 1980s as original equipment manufacturers (OEM) for overseas importers or as intermediaries between local manufacturers and overseas buyers until, starting in the 1990s, Hong Kong became a reexporter of toys made in China. In 1998, licensing and contract manufacturing for overseas manufacturers, usually to production specifications and product designs provided by the buyers, accounted for an estimated $70 \%$ of total domestic toy exports. ${ }^{12}$ US buyers accounted for $51 \%$

\footnotetext{
${ }^{10}$ Commission of the European Communities, 'Report from the Commission to the Council on the surveillance measures and quantitative quotas applicable to certain nontextile products originating in the People's Republic of China', COM(95)614 final, Brussels, 6.12.95,p 41.

${ }^{11}$ See Hong Kong Trade Development Council, Practical Guide to Exporting Toys for Hong Kong Traders (Hong Kong Trade Development Council, Research Department, March 1999), pp 34-58.

12 'Hong Kong's Toy Industry', Hong Kong \& China Economics, on the internet homepage of the Hong Kong Trade Development Council at
} 
of Hong Kong's toy exports in the first ten months of $1995 .^{13}$ Today Hong Kong is the location of management, design, $R \& D$, marketing, quality control, finance and usually shipping. ${ }^{14}$

At the bottom of the hierarchy are the factories, most of which are located in China. By 1995 toy production in China involved about 3,000 factories employing more than 1.3 million people. ${ }^{15}$ Such factories usually occupy the structural position of original equipment manufacturer (OEM) producing to other companies' specifications with machinery provided by the buyer. However, some now operate on the basis of original design manufacturer (ODM), producing to provided designs but sharing the cost of machinery and investment as well as sharing markets according to an agreement with the buyer. ${ }^{16}$ These contracts are often arranged and managed by Hong Kongbased entrepreneurs, who in addition to their role as intermediaries sometimes run their own toy manufacturing company in China and are also prominent in the main Hong Kong sectoral trade association, Hong Kong Toys Council. More than half of China's toy production is re-exported through Hong Kong. ${ }^{17}$ For this reason, as well as to preserve maximum

<http://www.tdc.org.hk/main/industries/t2_2_39.htm>, last updated 2 July 1998.

${ }^{13}$ Journal of Commerce, Friday, January 13, 1995, no page reference.

${ }^{14}$ See the statement by Dennis Ting, who as of January 1995 was chairman of Kader Industrial Co. Ltd., a leading Hong Kong toy firm, as well as of the Hong Kong trading agency's toy advisory committee and of the Hong Kong Toy Council: Journal of Commerce, Friday, January 13, 1995, no page reference.

${ }^{15}$ Jim Newton and Lai-hing Tse, ' 'Kids' Stuff: The Organisation and Politics of the China-EU Trade in Toys', in Roger Strange, Jim Slater, and Liming Wang (eds), Trade and Investment in China: The European Experience (Routledge, London and New York, 1998), pp at $147-165$ at 154.

${ }^{16}$ Interviews in Hong Kong, Guangzhou, and the Shenzhen Special Economic Zone, China.

${ }^{17}$ BBC Monitoring Service: Asia Pacific, 14 June 1995, cited in Newton and Tse, ' 'Kids' Stuff...' at 154 . 
flexibility in a highly innovative and rapidly changing market, the production of toys for the export market usually takes place in wholly owned subsidiaries rather than joint ventures. ${ }^{18}$ Today China and Hong Kong account for nearly $60 \%$ of world's toy trade. ${ }^{19}$

\section{The shape of global legal pluralism}

We usually view the legal arrangements which are relevant to such global economic networks in one of two ways. Often we see them essentially in terms of contracts between nominally equal parties, such as individuals, companies, or states, whose agreement is consecrated either in bilateral or multilateral form. Alternatively, we conceive of them in hierarchical terms, for example as constituting various regional or international forms of multilevel governance. I wish to suggest, however, that both of these conceptions, regardless of their force in normative terms, are descriptively inaccurate and analytically incomplete. There is a fundamental and growing disjunction between our traditional normative conceptions of the law governing international trade and the shape of the economic networks which are an integral part of economic globalisation. Global economic networks are the product of and a form of strategic behaviour, even though such networks usually have a particular locus of power and a specific hierarchy. In order to understand how they are governed in practice, we need to revise our basic ideas about the shape of the global legal order, without necessarily expecting economic relations and the law to be isomorphic.

\footnotetext{
${ }^{18}$ See Newton and Tse, ' 'Kids' Stuff...' at 153.

19 'Chinese Toy Making: Where the Furbies come from', The Economist, December 19, 1998, p. $95-99$ at 95.
} 
I suggest that the most adequate concept for understanding the global legal order is global legal pluralism. Global legal pluralism, as I use the term, ${ }^{20}$ comprises two different aspects. The first is structural, the second relational.

First, global legal pluralism involves a variety of institutions, norms, and dispute resolution processes located, and produced, at different structured sites around the world. Legal scholarship has traditionally paid most attention to understanding state, regional, and international (trade) legal institutions, legally binding norms, and dispute resolution processes involving law. The main exceptions in the legal world are international lawyers, who have also devoted much energy to the study of international negotiations and to norms that at least in principle are not legally binding. The analysis of international regimes, multi-level governance, and other types of institutional arrangements has largely been the province of political scientists and specialists in international relations. Examples in the field of EU legal scholarship include the work on multi-level governance, committees, and more generally on different types of settings, whether highly institutionalised with specified norms, rules and procedures or nonhierarchical and decentralised. While it is possible to generalise to some extent from this previous work, no one has tried to unite these different elements. Some basic questions remain therefore to be answered. What is a site? States and regional and international organisations are included, but so are a diversity of other institutional, normative, and processual sites, such as commercial arbitration, trade associations, and so on. How are sites created,

\footnotetext{
${ }^{20}$ My use of the term is broader than that of Gunther Teubner, "Global Bukowina": Legal Pluralism in World Society', in Gunther Teubner (ed), Global Law Without a State (Dartmouth, Aldershot, 1997. For further discussion of Teubner's stimulating ideas, see
} 
and how do they grow, survive or die? How are they structured? What does it mean to say that different structured sites are the anchors of contemporary legal pluralism?

Second, the relations among these sites are of many different types, in terms of both structure and process. For example, in terms of structural relationships, sites may be autonomous and even independent, part of the same or different regimes, part of a single system of multi-level governance, or otherwise interconnected. In terms of process, they may be distinct and discrete, competing, overlapping, or feed into each other, for example in the sense of comprising a 'structural set', 'formed through the mutual convertibility of rules and resources in one domain of action into those pertaining to another'. ${ }^{21}$ These relations of structure and process constitute the global legal playing field. They determine the basic characteristics of global legal pluralism, such as equality or hierarchy, dominance or submission, creativity or imitation, convergence or divergence, and so on. They influence profoundly the growth, development, and survival of the different sites.

Global legal pluralism is not merely an important part of the context in which global economic networks are constructed, in the sense that it is a factor to be taken into account by strategic actors. It is integral to these global economic networks themselves. In other words, global economic networks are constructed on a global playing field, which is organised or

my 'Governing Globalisation....

${ }^{21}$ Anthony Giddens, 'A Reply to My Critics', in David Held and John B. Thompson, Social Theory of Modern Societies: Anthony Giddens and His Critics (Cambridge 
structured partly by global legal pluralism. Global legal pluralism does more, however, than simply provide the rules of the game. It also constitutes the game itself, including the players.

\section{Global legal pluralism and the global commodity chain in toys}

\subsection{The theory of commodity chains}

We are now in a position to consider in more detail the interconnection between global legal pluralism and the global commodity chain in toys. Let us, following Hopkins and Wallerstein, use the term 'boxes' to refer to the separable processes involved in the international toy industry. ${ }^{22}$ The boundaries of each box are socially defined, and so may be redefined. ${ }^{23}$ Technological and social organisational changes play a role in these processes. So too, does law. Conceived broadly to encompass the sites of global legal pluralism, with each site comprising its specific institutions, norms and processes. Law helps to construct and to define the boxes which make up the global commodity chain in toys.

Hopkins and Wallerstein ${ }^{24}$ propose a series of questions concerning the social organisation of the constituent units of any single box in the chain.

1. Number of components units in each box

2. Geographic concentration or dispersal

\footnotetext{
University Press, 1989), pp 253-259 at 299.

${ }^{22}$ Terence K Hopkins and Immanuel Wallerstein, 'Commodity Chains: Construct and Research', in Commodity Chains in the Capitalist World-Economy Prior to 1800', in Gary Gereffi and Miguel Korzeniewicz (eds), Commodity Chains and Global Capitalism (Greenwood Process, Westport, CN, 1994), 17-20 at 18.

${ }^{23}$ Hopkins and Wallerstein, 'Commodity Chains...', at 18.

${ }^{24}$ Hopkins and Wallerstein, 'Commodity Chains...', at 18-19.
} 
3. Membership in one or more chains

4. Property arrangements

5. Modes of labour control

6. Links between different chains

I add two further issues:

7. Connection between economic relations and specific sites

8. Relations between sites and the chain as a whole

Thus here I rephrase, elaborate, and add to Hopkins' and Wallerstein's questions, giving special emphasis to the institutional, normative, and processual components of the sites of global legal pluralism. I offer selected examples of the interconnections between these sites and the international commodity chain. The discussion is meant to be illustrative, not exhaustive.

\subsection{Number of component units}

First, the number of component units in the box. To what degree is a box monopolised by a small number of production units? What are the main factors determining this structure? What incentives for a particular structure are provided by legal and other institutions, norms, and processes? Do different sites of global legal pluralism provide conflicting incentives, and if so, how are these conflicts managed, if not neutralised? If demonopolisation of any highly profitable box is an important process in the contemporary world economy, as Hopkins and Wallerstein suggest, ${ }^{25}$ what role do the sites of global legal pluralism play with regard to this process, for example by encouraging it, by countering it by redefining the boundaries of the box or

\footnotetext{
${ }^{25}$ Hopkins and Wallerstein, 'Commodity Chains...', at 18.
} 
by other means, or by creating incentives for shifting capital investment to other boxes, or even other chains?

Several sites of global legal pluralism play a role in shaping or determining the number of component units in any given box in the international commodity chain in toys. Consider three examples. First, United States intellectual property law is of crucial significance in determining the number of buyers and maintaining their market power. Second, antitrust law is crucial in defining the number of key buyers or manufacturers in the international toy industry. American competition law affects the possibility of mergers among buyers. When market leader Mattel Inc acquired the third largest toy manufacturer, Tyco Toys Inc., in 1996, Mattel was quoted in the American media as expressing confidence that the deal would not be blocked by US antitrust law, even though the companies' combined sales represented $19 \%$ of the US toy market. ${ }^{26}$ Third, the lack of binding legal regulation of Internet retailing lowers barriers to entry into the retail market in toys. Consequently, when buyers are squeezed by traditional retailers, they turn without great difficulty to the Internet in order to enter the retail sector themselves, either through specialist Internet retailers or by means of the buyers' own websites.

\subsection{Geographic concentration or dispersal}

Second, geographic concentration or dispersal. What is the degree of geographic spread of the units in a specific box? In other words, are the units in a specific box geographically concentrated, or are they dispersed? For

\footnotetext{
${ }^{26}$ James Madore, 'Mattel confident Tyco deal will pass antitrust scrutiny', The Buffalo News, Tuesday, November 19, 1996, no page reference.
} 
example, are the provision of finance, marketing, and retailing geographically concentrated, while production is dispersed? Is the prevailing geographic pattern influenced by the sites of global legal pluralism, and if so, how? For example, what incentives do different institutions, norms, and processes provide for either concentration or dispersal of the different sites? Do these institutions, norms, and processes play a role in the extent to which boxes shift from the core to the periphery of the world economy, assuming that, as Hopkins and Wallerstein argue, a box is likely to be relatively geographically concentrated in the core but dispersed on the periphery?

We have already seen that invention, finance, marketing, and retailing in the international toy industry are concentrated, the first in the USA, the second and third in the USA and Hong Kong, and the last, so far as control is concerned, in the USA and to a much lesser extent Europe and Japan. Production, however, is potentially much more dispersed, even though until recently it has tended to be concentrated in Asia. The geographical separation of production from finance, marketing, and retailing is encouraged by international norms concerning the customs operations known in the EU as inward processing and outward processing. ${ }^{27}$ It is no exaggeration to describe the existence and increased use of these customs rules as the legal basis for what has been called 'the new international division of labour'. ${ }^{28}$ The overarching international legal framework is

\footnotetext{
${ }^{27}$ On EU law, see Francis Snyder, International Trade and Customs Law of the European Union (Butterworths, London, 1998), 83-103.

${ }^{28}$ For case studies from an economic standpoint, see Folker Froebel, Juergen Heinrichs, and Otto Kreye, The New International Division of Labour: Structural Unemployment in Industrialised Countries and Industrialisation in Developing Countries (trans. Pete Burgress) (Cambridge, Cambridge University Press; Editions de la Maison des Sciences de l'Homme, Paris, 1980.
} 
provided by the International Convention on the Simplification and Harmonization of Customs Procedures, which was signed at Kyoto on 18 May 1973 and entered in force on 25 September $1974 .{ }^{29}$ The CCC now has about ninety members, including the US, the EC and its Member States, Hong Kong, and China. Not all of these, however, are party to all the relevant annexes, such as Annex E.6 concerning temporary admission for inward processing, Annex E.8 concerning temporary exportation for outward processing, and Annex F.1 concerning free zones.These annexes contain the basic substantive rules, which are not legally binding but may take effect as standards, recommended practices, or notes.

China has ratified the Convention but has not accepted any of these three annexes. Since the early 1980s, however, Chinese legislation, both central and local, on Special Economic Zones has had a direct influence on the concentration of production facilities in the international toy trade. Most toy factories are located in the Shenzhen SEZ. Shenzhen rules on foreign direct investment (FDI) provide for Chinese-foreign joint ventures, Chineseforeign contractual joint ventures, wholly foreign-owned enterprises, international leasing, compensation trade, and processing and assembling with materials and parts from foreign suppliers. ${ }^{30}$ Recently, however, the fact that labour costs in Shenzehn are higher than in the rest of Guandong Province, due partly to law, has encouraged toy companies to establish outside the SEZ, though still in Guandong.

\footnotetext{
${ }^{29}$ OJ EC 1975 L100/2; Cmnd 5938.

${ }^{30}$ For an introduction, see the Shenzhen SEZ Internet homepage at $<$ http://chinawindow.com/Shenzhen-w/shenzhen.html.>
} 


\subsection{Membership in one or more chains}

Third, membership of one or more chains. Is a box located in more than one commodity chain? If so, how many? Do specific sites, including institutions, norms, and processes, create a structure of incentives so that a particular box tends to be inserted in more than one commodity chain, nor not? To what extent, and how, is this insertion of a particular box in different commodity chains accomplished partly by the law? What role do law and other types of norms play in the management of relations between the different commodity chains in which a particular box is located?

\subsection{Property arrangements}

Fourth, property arrangements. What property-like arrangements (such as use, ownership, management, control) are associated with the units of a specific box? Which sites of global legal pluralism are the most relevant to these arrangements? Which specific institutions, norms, and processes are determinative with regard to the arrangements in a particular site? Why? If different property-like arrangements prevail among the various units in a box, what institutions, norms, and processes encourage or tolerate diversity? How is such diversity managed?

\subsection{Modes of labour control}

Fifth, modes of labour control. What modes of labour control are found in each box? Which sites of global legal pluralism are most relevant, and why? Which specific institutions, norms, and processes are significant, and why? To what extent are different modes of labour control encouraged or faciliated by legal or other institutions, norms, and processes? Are there conflicts among different sites with regard to modes of labour control? If so, 
how are these conflicts resolved in institutional, normative, and processual terms?

The labour law of nation-states is not the only relevant law, or in the case of China even the most important. Far more significant are the codes of conduct elaborated under the aegis of multinational companies and sectorspecific trade associations. They reflect the organisation of power in the global toy commodity chain in two respects. First, the dominant buyers, whose power rests on their control of brands and marketing, are able in effect to determine the content of industry-wide codes of conduct and impose them on their suppliers. Codes of conduct thus are analogous to standard-form contracts laid down by the leading firms in a particular market. ${ }^{31}$ Second, precisely because the dominant buyers are few in number, they are unusually susceptible to political pressure. Non-governmental organisations, such as the Toy Coalition, have successfully put pressure on the small number of powerful American buyers, and the national and international trade associations they control, to elaborate codes of conduct with regard to their mainly Asian workforce.

\subsection{Links between different chains}

Sixth, links between different commodity chains. How are the boxes within a particular commodity chain linked to each other? Which specific institutions, norms, and processes create, sustain, or transform these links? What role do different sites of global legal pluralism play in linking different boxes? Is there any overall coordination of these links? How is the

31 Peter T Muchlinski, "'Global Bukowina" Examined: Viewing the Multinational Enterprise as a Transnational Law-making Community', in Gunther Teubner (ed), Global 
discreteness of a particular commodity chain maintained, and what role does global legal pluralism play in this respect?

\subsection{Connections between economic relations and specific sites}

A seventh set of questions concerns specifically the connections between particular sets of economic relations (boxes) and specific sites of global legal pluralism. Do specific sites concern particular aspects of specific boxes? For example, do certain sites deal with labour control, others with financial arrangements, others with marketing, others with dispute resolution, and so on? How, and why? To what extent are particular sites important in governing the social organisation of the constituent units of a box even when the sites are not geographically proximate to the box, in other words when governance, economic processes, and territory are not congruent?

Four examples illustrate the relationship between the marketing of toys and the EU as a legal site. First, quotas were applied to imports into the EU of toys from China until 1998, provoking a series of cases before the European Court of Justice. ${ }^{32}$ Second, the EC 'toys directive' ${ }^{\prime 33}$ provides that all toys sold in the EU must meet essential safety requirements and bear a 'CE' mark indicating conformity. It conditions Chinese production of toys for export to Europe and the conduct of inspections in Hong Kong. ${ }^{34}$ Third, with regard to EC environmental legislation, though no EU legislation has been yet been

\footnotetext{
Law Without a State (Dartmouth, Aldershot, 1997) 79-108 at 86.

${ }^{32}$ For a detailed analysis, see Francis Snyder, 'Governing Globalisation...'.

${ }^{33}$ Council Directive 88/378/EEC, as amended.

${ }^{34}$ See 'Hong Kong's Toy Industry', Hong Kong \& China Economics, on the internet homepage of the Hong Kong Trade Development Council at <http://www.tdc.org.hk/main/industries/t2_2_39.htm>, last updated 2 July 1998.
} 
enacted in response to pressure from Greenpeace to ban all soft PVC toys for children in the EU, the risk that it might be has already changed the practices of some toy factories in China which export to the EU. ${ }^{35}$ Fourth, general EC trade legislation affects Chinese toy exports. As from January 1998, preferences for certain Chinese goods were removed under the EC's Generalised Scheme of Preferences (GSP), leading to an increase in the tariff rate for toys to levels varying between $3.4 \%$ and $6.3 \%{ }^{36}$

\subsection{Relations between sites and the chain as a whole}

Eighth, relations between sites and the chain as a whole. What types of relationships, for example horizontal or vertical, competitive or cooperative, marked-based or state-based or convention-based, exist between the different sites that are relevant to a specific global commodity chain? Does any specific site concern the global commodity chain as a whole? To what extent does the plurality of sites provide an effective way of managing the chain as a whole? Would a single site or a small number of sites be more effective? What does 'effective' mean in this context? In other words, what are our criteria for evaluating the effectiveness of specific sites, and of the totality of sites which we call global legal pluralism, in the organisation and management of the chain as a whole?

Certain sites concern several parts of the chain or the chain as a whole. The most well-known example is the Uruguay Round agreements associated with the World Trade Organization (WTO). This includes the General Agreement

\footnotetext{
${ }^{35}$ Interviews in Guangzhou and Shenzhen Special Economic Zone, China.

36 'Hong Kong's Toy Industry', Hong Kong \& China Economics, on the internet homepage of the Hong Kong Trade Development Council at <http://www.tdc.org.hk/main/industries/t2_2_39.htm>, last updated 2 July 1998.
} 
on Tariffs and Trade (GATT), the General Agreement on Trade in Services (GATS), and the Agreement on Trade-Related Aspects of Intellectual Property (TRIPS).

The GATT/WTO was a crucial conditioning element in the negotiation of the EU quota on toys from China in 1993-94 and the related litigation between 1994-1998. ${ }^{37}$ It also cast a long shadow with regard to future disputes, notably by holding out, to China and multinational companies 'located' there, the promise of new institutions, norms, and processes which would be available on eventual Chinese accession. When China joins the GATT, the firms located there will benefit from Article XI GATT concerning the general elimination of quantitative restrictions. The provision of services and the protection of intellectual property in brand names are likely to be affected by the eventual application of GATS and TRIPS. It may also be argued that the impact of the GATT on China is already real, even if China has not yet acceded to the WTO. Companies are already positioning themselves in anticipating of further opening up of China's domestic market to imported toys and foreign toy retailers. One has only to note that in 1997, the same year it purchased a major competitor Tyco, Mattel launched Barbie in China. ${ }^{38}$

\section{Conclusion}

I have argued here that global economic networks are governed by the totality of strategically determined, situationally specific, and often episodic conjunctions of a multiplicity of institutional, normative, and processual

\footnotetext{
${ }^{37}$ For detailed analysis, see Francis Snyder, 'Governing Globalisation...' .

${ }^{38}$ See the history of Mattel on the company internet homepage at
} 
sites throughout the world. The totality of such sites represents a new global form of legal pluralism.

The development of the global economic relations involved in the international toy industry owes much to corporate strategies. But these strategies themselves have been pursued taking account of the framework of the law and have been elaborated by using the law. They take place, are conditioned by, and have contributed to the development of global legal pluralism. To put it more accurately, the development of global networks in the toy industry has occurred in conjunction with the development of a variety of structural sites throughout the world, each of which comprises institutions, norms, and dispute resolution processes.

Taken together, these different but interwoven sets of norms, whether legally binding in formal terms or soft law, amount to a distinct regime for governing global economic networks. They are, however, less a structure of multi-level governance than a conjunction of distinctive institutional and normative sites for the production, implementation and sanctioning of rules. In the specific case of the toy industry, they testify, in part, to the structure of authority and power within these inter-firm and intra-firm networks, which are characterised by a buyer-driven, rather than a producer-driven, governance structure. These new normative forms for governing global economic networks are among the reasons why the American, EU, and Chinese firms and economies are so intimately linked in the internationalised production and distribution relations which are characteristic of globalisation. 
Several more specific hypotheses can be derived from this discussion. First, global legal pluralism is a way of describing the structure of the sites taken as a whole. Seen from the perspective on a specific global commodity chain, global legal pluralism may be described as a network, even if some segments of the network may be occuped alternatively by two or more possible sites.

Second, the sites of global legal pluralism may be classified provisionally into three rough categories. Some sites are market-based, being generated by economic actors as part of economic processes. Some are polity-based, in that they form a part of established political structures. Others are convention-based, deriving from agreements between governments. This classification scheme distinguishes between different types of sites according to their mode of creation.

Third, the various sites differ in decision-making structure, that is, in their institutions, norms and processes. These factors affect the outcomes of the various sites, including the different ways in which they allocate risk. At the same time, however, it is important not to overlook the extent to which sites are interrelated, for example in relation to institutional arrangements such as jurisdiction, copying or borrowing of norms, and the interconnection of their dispute-resolution processes.

Fourth, the sites are not all equally vulnerable to economic pressures. It is going too far to say that the network of global legal pluralism which is put into play by the economic processes of any specific global commodity chain reflects the structure of authority and power in the global commodity chain 
in question. Some types of institutions, some types of processes, and some types of norms are more permeable to economic processes than others.

Fifth, the economic organisations occupying the same box in a global commodity chain are sometimes if not often in conflict. These conflicts involve and have important implications for sites. For example, conflicts over markets may pit foreign producers, exporters and importers, on one hand, against domestic producers, on the other hand. Conflicts over markets also occur between companies occupying similar positions in the chain The occupants of each of these segments try to enlist the norms, institutions and processes of the various sites of global legal pluralism to improve their position, not only vis-à-vis their direct competitors but also in relation to the occupants of other segments of the global commodity chain.

Sixth, taken as a whole, the various sites are not necessarily hierarchically ordered in relation to each other. Instead, they demonstrate many other types of interrelationships, both symmetrical and asymmetrical, as is the case with many aspects of transatlantic regulatory cooperation between the EU and the USA. In other words, they do not make up a legal system, even viewed in a more general perspective. This contrasts strongly with the usual lawyer's view of the multi-level governance of international economic relations. On such a view, in so far as they involve EU and US firms and governments, they are governed by a hierachically ordered combination of EU, US, and WTO law. Or if they involve EU firms, they are governed mainly by a hierarchically ordered combination of WTO law, EU law and the law of the EU Member States. That is a normative perspective. It is different from the more sociological perspective that I have tried to develop here. 
Seventh, these sites are not always, or even usually, alternatives in dispute resolution, as might be expected if one presumes that the norms governing global economic networks are ordered in a hierarchical arrangement. Instead, each site deals with, governs, or seeks to govern a discrete part of the global commodity chain. Once a chain is established, its activities are governed by a given set of rules, emanating from a variety of linked sites, except to the extent that private international law and normal conflicts of law rules allow firms a choice of governing legislation or a choice of dispute resolution.

Numerous questions remain to be addressed by future research. For example, how are sites created? How are they constituted, developed, and legitimated as sites? Do sites have a specific geographical location, and if so, why? What decision processes are involved? Do they vary in their resemblance to state law (insertion in a hierarchy, reliance on case law, binding decisions, use of precedent, etc.), and why? To what extent do the norms of a particular site combine hard law and soft law? To what extent are sites interconnected, and how are they connected? What determines the modes and organisation of dispute resolution? The answers to these questions will help us to understand further how global economic networks are governed. 